To the Editors:

\title{
Oral squamous cell carcinoma among patients in Sri Lanka: a retrospective analysis
}

\author{
N H Senarath ${ }^{1}$, P R Jayasooriya ${ }^{1}$, R D Jayasinghe ${ }^{2}$, P D Amaratunga ${ }^{1}$ \\ Ceylon Medical Journal 2018; 63: 102-104
}

DOI: http://doi.org/10.4038/cmj.v63i2.8679

\section{Introduction}

Oral mucosae are affected by a wide variety of pathological conditions, including malignancies. Oral squamous cell carcinoma accounts for over $90 \%$ of such lesions [1]. The existing literature on lesions of the tongue provide information on different types of pathologies, their symptoms and associations with habits as well as systemic conditions [2-4]. However, literature on lesions of the tongue based on histopathological diagnoses is sparse $[5,6]$.

The aim of this study was to analyze demographic features and observe the concordance between clinical and histopathological diagnoses of lesions of the tongue where the clinical impression could be similar or dissimilar with regards to the malignant or benign nature of the lesion, as identified histopathologically.

\section{Methodology}

This is a retrospective descriptive analysis of data of all histopathologically confirmed lesions of the tongue in the archives of the Department of Oral Pathology, Faculty of Dental Sciences, University of Peradeniya. Out of a total of 6931 biopsies received during 2010-2012, lesions of the tongue accounted for 898 (12.95\%) lesions.

After excluding repeat biopsies, cases with no definitive diagnoses and insufficient clinical information, study sample comprised of 780 biopsies.

Demographic data, site and type of lesion, clinical diagnosis and definitive histopathological diagnoses were extracted from the biopsy request forms and the pathology data base. Statistical significance was assessed using chi square tests.

\section{Results}

\section{Age distribution of lesion of the tongue}

Lesions of the tongue occurred in a wide age range of patients (1-96 years). A statistically significant, majority of $351(45.58 \%)$ occurred in the 51-70 year age group compared to other age groups $(p<0.0001)$. Reactive lesions were the commonest category in the age groups below 30 years of age. In patients aged $>30$ years malignant epithelial tumours were the commonest diagnoses.

\section{Gender distribution}

The male to female ratio was 1.66: 1. Malignant tumours and oral potentially malignant disorders occurred significantly more often in males while reactive lesions and benign tumours affected both sexes almost equally.

\section{Clinical presentations of tongue lesions}

The commonest clinical presentation was growths $269(34.48 \%)$, followed by ulcers $238(30.51 \%)$. White lesions accounted for 109 lesions (13.97\%). Twelve (1.5\%) were white and red lesions.

Lesions of the tongue were mainly localized pathologies. Majority presented as single lesions. Oral sub mucous fibrosis $(n=9)$, oral lichen planus $(n=9)$ and oral squamous cell carcinoma $(n=7)$ presented as generalized lesions on the tongue as well.

\section{Surface distribution of tongue lesions}

Lesions of the tongue occurred on different surfaces. Three hundred and forty seven $(44.54 \%)$ lesions occurred on the lateral surface. Reactive lesions were the commonest on dorsal and ventral surfaces. Epithelial malignancies showed a characteristic affinity toward the lateral surface while oral potentially malignant disorders were common in both dorsal and lateral surfaces (Table 1).

${ }^{1}$ Department of Oral Pathology, Faculty of Dental Sciences, University of Peradeniya, ${ }^{2}$ Department of Oral Medicine, Faculty of Dental Sciences, University of Peradeniya, Sri Lanka.

Correspondence: NHS, e-mail: <z.nimna.s@gmail.com>. Received 04 May 2018 and revised version accepted 04 May 2018. 
Table 1. Characteristics of the lesions

\begin{tabular}{|c|c|c|c|c|c|}
\hline & $\begin{array}{c}\text { Oral squamous } \\
\text { cell carcinoma } N(\%)\end{array}$ & $\begin{array}{c}\text { Fibroepithelial } \\
N(\%)\end{array}$ & $\begin{array}{c}\text { Mucocoel } \\
\text { polyp } N(\%)\end{array}$ & $\begin{array}{l}\text { Oral lichen planus } \\
\qquad N(\%)\end{array}$ & $\begin{array}{c}\text { Leukoplakia } \\
\qquad N(\%)\end{array}$ \\
\hline \multicolumn{6}{|c|}{ Age groups } \\
\hline $0-16$ & $0 \%$ & $13(13.3 \%)$ & $47(77 \%)$ & $3(5.1 \%)$ & $0 \%$ \\
\hline $17-30$ & $2(0.8 \%)$ & $12(12.2 \%)$ & $10(16.4 \%)$ & $12(20.3 \%)$ & $1(1.3 \%)$ \\
\hline $31-50$ & $69(26.8 \%)$ & $41(41.8 \%)$ & $1(1.6 \%)$ & $21(35.6 \%)$ & $17(22.4 \%)$ \\
\hline $51-70$ & $160(62.3 \%)$ & $30(30.6 \%)$ & $3(4.9 \%)$ & $1(30.5 \%)$ & $47(61.8 \%)$ \\
\hline$>71$ & $26(10 \%)$ & $2(2 \%)$ & $0 \%$ & $4(6.8 \%)$ & $11(14.5 \%)$ \\
\hline \multicolumn{6}{|l|}{ Gender } \\
\hline Male & $201(78.2 \%)$ & $37(37.8 \%)$ & $36(59 \%)$ & $27(45.8 \%)$ & $51(67.1 \%)$ \\
\hline Female & $54(21 \%)$ & $61(62.2 \%)$ & $25(41 \%)$ & $32(54.2 \%)$ & $24(35.5 \%)$ \\
\hline \multicolumn{6}{|l|}{ Surface } \\
\hline Dorsal & $49(19 \%)$ & $48(49 \%)$ & $51(83.6 \%)$ & $16(26.7 \%)$ & $16(20.3 \%)$ \\
\hline Ventral & $53(20.9 \%)$ & $10(10.2 \%)$ & $7(11.4 \%)$ & $21(35 \%)$ & $21(26.6 \%)$ \\
\hline Lateral & $151(58.1 \%)$ & $3(38.8 \%)$ & $0 \%$ & $17(28.3 \%)$ & $39(49.4 \%)$ \\
\hline
\end{tabular}

Note: Lesions which were histopathologically diagnosed as keratosis (with or without dysplasia), and clinically identified as leukoplakia are included in this table under the category Leukoplakia.

\section{Type of histopathological diagnoses}

Out of 264 malignant epithelial lesions, the commonest pathological condition was oral squamous cell carcinoma, $258(78.41 \%)$. This was also the commonest lesion diagnosed in this study (33.07\%).

The characteristics pertaining to granular cell tumours, that mimics oral squamous cell carcinoma was analyzed. The male to female ratio was $1: 1.6$ and $5(62.5 \%)$ patients were above 30 years of age. Five $(62.5 \%)$ were present on the lateral surface. Two of the lesions mimicked malignancy, clinically.

\section{Concordance between clinical and histopatho- logical diagnoses}

Clinical diagnosis of malignancy showed over prediction by $5.5 \%(n=43)$. Similarly, $1.2 \%(n=9)$ of histopathologically malignant lesions had been clinically diagnosed as benign lesions.

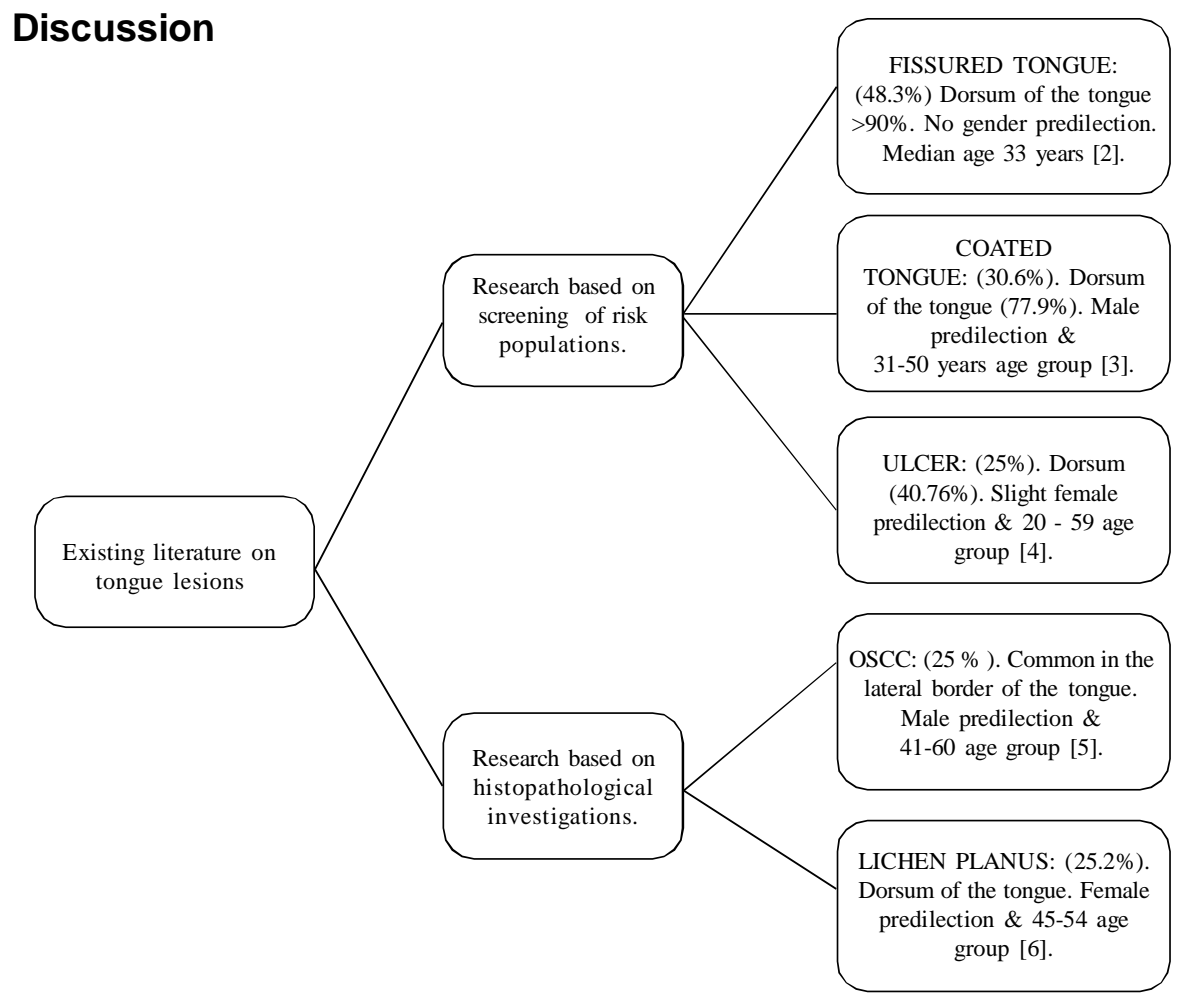

Figure 1. Summary of the recent literature on lesions of the tongue. 
Published studies either report findings from screening of patients or studies of histopathological reports (Figure 1). Accordingly, approximately, $75 \%$ of the available literature state male predominance in lesions of the tongue [2-6]. A study based on biopsy reports shows male predilection where the commonest diagnosis is oral squamous cell carcinoma [5]. In contrast, female predilection is reported in another study, where the commonest diagnosis was oral lichen planus [6]. However we can relate this gender predilection to the specific pathology.

The age distribution of lesions of the tongue demonstrated a wide range, with specific pathologies such as oral squamous cell carcinoma seen in adults. This is an important aspect that should be considered when clinicians arrive at differential diagnoses.

Oral squamous cell carcinoma was diagnosed as the commonest lesion which commonly occurred on the lateral surface. These findings are similar to those reported in other studies. This may be due to the retaining of betel quid in the sulcular region causing chronic exposure to carcinogens.

Oral squamous cell carcinoma, fibroepithelial polyp, mucocele, leukoplakia and oral lichen planus / lichenoid reaction are the commonest conditions found in this study and this is similar to findings in other studies. However, some studies based on clinical examination, have reported common benign reactive conditions such as fissured tongue. This raises several questions. Are benign conditions noted as more common on clinical examination because oral squamous cell carcinoma is not easily detected during examination?

Nevertheless, studies involving South Asian populations like India too have detected benign lesions to be more common on clinical screening of the tongue [3]. Lack of histopathological evaluation of lesions of the tongue make these results relatively less convincing. If clinical screening is followed by biopsies this may help explain the disparity between clinical and histological findings.

An important aspect in the current study is the assessment of the concordance between clinical and histopathological diagnoses. In Sri Lanka, clinicians must carry out a thorough oral examination because of the high incidence of oral squamous cell carcinoma. There was clinical over diagnosis of malignant conditions of $5.5 \%$, where benign lesions were clinically identified as malignant. Even though treatment would not be commenced until a definitive diagnosis is made, this may cause anxiety and distress to the patients. Under-diagnosis of malignant conditions is more problematic. We found that $1.2 \%$ of malignant tumors were considered as benign on clinical assessment. However, this percentage does not indicate the actual number of under diagnosed oral squamous cell carcinomas because most such patients would not be subjected to biopsy.

\section{Conclusion}

Oral squamous cell carcinoma is the commonest histopathologically diagnosed disease of the oral tongue in this sample. The commonest oral potentially malignant disorder was leukoplakia. Therefore, clinicians should be aware of these possibilities when examining the lesions of the tongue. Future research should consider screening of a risk population followed by histopathology where necessary.

\section{Conflicts of interest}

Authors declare that there are no conflicts of interest.

\section{References}

1. Tilakaratne WM, Warnakulasooriya S. Oral medicine and Oral pathology. A guide to diagnosis and management. 1st ed. Jaypee brothers, 2014.

2. Byahatti SM, Ingafou MSH. The prevalence of Tongue lesions in Libyan adult patients. J Clin Exp Dent 2010; 2(4): 163-8.

3. Bhattacharya PT, Sinha R. Prevalence and subjective knowledge of tongue lesions in an Indian population. $J$ Oral Biol Cranio Fac Res 2106; 6(2): 124-128.

4. Fuoad SA. A clinical study on tongue lesions among Iraqi dental Outpatients. RRJDS 2014; 2(1): 101-6.

5. Shamloo N, Lotfi A, Motazadian HR. Squamous cell carcinoma as the most common lesion of the tongue in Iranians : a 22 year retrospective study. Asian Pac J Cancer Prev 2016; 17(3): 1415-16.

6. Alaeddinni M, Barghammadi R, Eshghyar N, EtemadMaghadams. An analysis of biopsy proven tongue lesions among 8,105 dental outpatients. J Contemp Dent Pract 2014; 15(1): 1-7. 